\title{
Pengaruh Perilaku Inovatif pada Keberhasilan Womenpreneur Etnis Madura sebagai Pedagang Pakaian Jadi
}

\author{
Tri Siwi Agustina \\ Universitas Airlangga \\ E-Mail : siwi@feb.unair.ac.id
}

\begin{abstract}
Abstrak
Perdagangan seringkali dianggap sebagai sesuatu yang menjanjikan untuk mendatangkan kekayaan. Salah satu faktor yang menyebabkan keberhasilan pedagang adalah karena perilaku inovatif. Penelitian ini bertujuan untuk mengetahui pengaruh perilaku inovatif terhadap keberhasilan wanita beretnis Madura di ITC Mega Grosir Surabaya. Variabel penelitian ini terdiri dari perilaku inovatif terdiri dari opportunity exploration, generativity, formative investigation, championing, dan application. Sampel penelitian ini adalah 95 wanita pedagang beretnis Madura Pengujian hipotesis mengunakan metode analisis regresi linier berganda. Hasil penelitian menunjukkan variabel opportunity exploration, generativity dan formative investigation tidak menunjukkan pengaruh pada keberhasilan sedangkan variabel championing dan application terbukti berpengaruh pada keberhasilan womenpreneur etnis Madura yang berdagang pakaian jadi di ITC Mega Grosir Surabaya.
\end{abstract}

Kata kunci : perilaku inovatif, keberhasilan usaha, wanita pedagang etnis Madura

\section{Pendahuluan}

Berdagang merupakan salah satu cara seseorang untuk mencapai kesuksesan dan kemakmuran hidup sehingga akhirnya banyak orang yang mencoba terjun ke dunia perdagangan. Salah satu hal yang menyebabkan keberhasilan seorang wirausaha/ pedagang diantaranya adalah perilaku inovatif.

Saat ini dunia usaha, khususnya perdagangan tidak hanya dimonopoli oleh kaum pria, kaum wanita juga telah terjun ke dunia ini. Keterlibatan kaum wanita di dunia bisnis memberikan warna tersendiri serta semakin diperhitungkan dalam dunia perdagangan di Indonesia. Ketertarikan tersebut lebih didasarkan pada apa yang melatarbelakangi keberadaan mereka serta nilai-nilai budaya yang melatarbelakanginya. Selain itu, tanggung jawab wanita dalam menjalankan bisnis sekaligus tanggung jawabnya sebagai pribadi yang tidak terlepas dari peran domestik menyebabkan terganggunya konsentrasi dan semakin terbatasnya waktu untuk melakukan kegiatan inovasi (Tambunan, 2009).

Di ITC Mega Grosir Surabaya terdapat berbagai macam etnis yang melatarbelakangi wanita pedagang yang ada disana. Salah satu etnis dari wanita pedagang yang cukup banyak di ITC Mega Grosir Surabaya adalah etnis Madura. Seperti pada umumnya orang etnis Madura yang dikenal sebagai pekerja keras, ulet, tekun, sederhana serta tidak menyia-nyiakan kesempatan (Sutarto, 2006), wanita Madura dengan latar belakang sosial ekonomi tinggi atau rendah, berpendidikan tinggi atau rendah, yang tinggal di Madura ataupun telah bermigrasi ke pulau lain adalah pekerja keras baik untuk pekerjaan rumah tangga maupun pencari nafkah. Etos kerja yang tinggi pada wanita Madura didorong dengan keyakinan bahwa kerja adalah 
ibadah, amal serta sebagai bentuk perjuangan meraih pengakuan atas kemampuan dirinya (Sukesi, Wisaptiningsih dan Nurhadi, 2008). Berdasarkan latar belakang tersebut maka dirumuskan masalah sebagai berikut : (1) Apakah perilaku inovatif yang terdiri dari eksplorasi peluang, menghasilkan ide, uji coba, mental juara, dan pengaplikasian secara simultan berpengaruh terhadap keberhasilan womenpreneur etnis Madura etnis Madura; (2) Apakah perilaku inovatif yang terdiri dari eksplorasi peluang, menghasilkan ide, uji coba, mental juara, dan pengaplikasian secara parsial berpengaruh terhadap keberhasilan keberhasilan womenpreneur etnis Madura .

\section{Landasan Teori dan Pengembangan Hipotesis}

Wanita pedagang/wirausaha diartikan sebagai wanita dalam dunia bisnis yang mengambil peluang dan memulai, membangun dan menumbuhkan bisnis yang sukses. Meningkatkatnya partisipasi wanita dalam angkatan kerja menunjukkan bahwa nilai-nilai tradisional yang memandang wanita sebagai unsur domestik dan pria sebagai unsur publik kini semakin samar. Perempuan cenderung lebih menonjol dalam pergaulan (people oriented) dibanding laki-laki, menurut Stain (1989).

Pengertian perilaku inovatif menurut dalam De Jong \& Kemp (2003) adalah semua perilaku individu yang diarahkan untuk menghasilkan, memperkenalkan, dan mengaplikasikan hal-hal 'baru', yang bermanfaat dalam berbagai level organisasi. Perilaku inovatif sarat dengan berbagai tantangan dan proses menjalankannya tidak mudah. Beberapa peneliti menyebutnya sebagai shop-floor innovation dalam De Jong \& Den Hartog, 2003. Kleysen dan Street (2001) menguraikan aspek-aspek perilaku inovatif serta merangkum dari penelitian-penelitian sebelumnya aktivitas yang menyertai masing-masing aspek, sebagai berikut:

1) Eksplorasi Peluang/Opportunity Exploration diukur dengan indikator berikut : memberi perhatian pada sumber peluang (paying attention to opportunity sources); mengenali peluang (recognizing opportunities) dan berbagi informasi yang berkaitan dengan peluang (gathering information about opportunities

2) Menghasilkan ide/Generativity diukur dengan indikator : munculnya ide yang memiliki peluang (generating ideas and solutions to opportunities) ; membuat gambaran tentang gagasan serta mengelompokkannya (generating representations and categories of opportunities) dan menggabungkan gagasan dengan informasi (generating associations and combinations of ideas and informations)

3) Uji Coba/Formative Investigation diukur dengan indikator berikut: melakukan uji coba ide dan pemecahan masalah (experimenting with ideas and solutions), keaslian ide (originality of ideas), mengevaluasi ide dan pemecahan masalah (evaluating ideas and solutions).

4) Mental Juara (Championing) diukur dengan indikator berikut: mobilisasi berbagai macam sumber daya (mobilizing resources), meyakinkan dan memengaruhi orang lain (persuasing and influencing), melakukan sesuatu yang menantang dan menghadapi resiko (challenging and risk taking)

5) Pengaplikasian/Application diukur dengan indikator berikut: penerapan ide perubahan ke arah yang lebih menguntungkan (implementing), memodifikasi ide-ide yang sudah diterapkan dalam mengaplikasikan ide baru (modifying), Melakukan rutinitasi inovasi untuk memperbaiki proses, teknologi, produk dan layanan dalam kegiatan sehari-hari (routinizing) 


\section{Tri Siwi Agustina}

Walker dan Brown (2004) merumuskan keberhasilan usaha dari wanita pengusaha/pedagang meliputi dimensi sebagai berikut :

1. Kualitas Hidup (Quality of Life) yang terdiri dari : membantu perekonomian keluarga, mendapatkan kepuasan pemenuhan diri, termasuk pemenuhan tuntutan spiritual atau religius, dan peningkatan taraf hidup keluarga

2. Kebebasan (Autonomy) seperti : bebas dari segala aturan organisasi, Bebas mengatur waktu dan bebas mewujudkan ide-ide sendiri

3. Kepuasan Kerja (Job Satisfaction) yang terdiri dari : kepuasan pribadi lebih penting daripada menghasilkan banyak uang (citra diri), memberikan orang lain pekerjaan memberikan kepuasan pribadi dan berguna bagi orang lain, dan menaklukan tantangan

Teoh dan Chong (2008) menjelaskan bahwa jaringan kerja (networking) merupakan hal yang terpenting dalam menjamin keberlangsungan hidup dan usaha yang dibangun oleh wanita.

4. Jaringan Kerja (Networking), yang terdiri dari : manfaat mengenal banyak orang bagi diri sendiri, manfaat mengenal banyak orang bagi pengembangan bisnis, keikutsertaan dalam perkumpulan formal dan informal, baik perkumpulan usaha sejenis ataupun tidak.

Walker dan Brown (2004) merumuskan keberhasilan usaha dari wanita pengusaha/pedagang meliputi dimensi sebagai berikut:

5. Kemampuan untuk seimbang dalam bekerja dan keluarga (The ability to balance work and family) dengan pengukuran sebagai berikut : menyadari adanya tuntutan peran antara pekerjaan-keluarga, mampu membagi waktu antara pekerjaan dan keluarga (keseimbangan waktu) dan kewajiban pekerjaan yang sering merubah rencana bersama keuarga (keseimbangan tugas dan tanggung jawab)

Sandjaja dan Riyanti (2004) menyatakan bahwa perilaku inovatif memberi kontribusi yang signifikan pada keberhasilan usaha. Sebagaimana pendapat Drucker yang dikutip dalam Idris (2009) yang menyebutkan bahwa keterampilan inovasi merupakan salah satu atribut kritis dalam membentuk keberhasilan wirausaha.

Berdasarkan pernyataan tersebut diatas maka dirumuskan hipotesis sebagai berikut :

H1 : Perilaku Inovatif yang terdiri dari eksplorasi peluang, menghasilkan ide, uji coba, mental juara, dan pengaplikasian secara simultan berpengaruh signifikan terhadap keberhasilan womenpreneur etnis Madura.

H2 : Perilaku Inovatif yang terdiri dari eksplorasi peluang, menghasilkan ide, uji coba, mental juara, dan pengaplikasian secara parsial berpengaruh signifikan terhadap keberhasilan womenpreneur etnis Madura 


\section{Kerangka Berpikir}

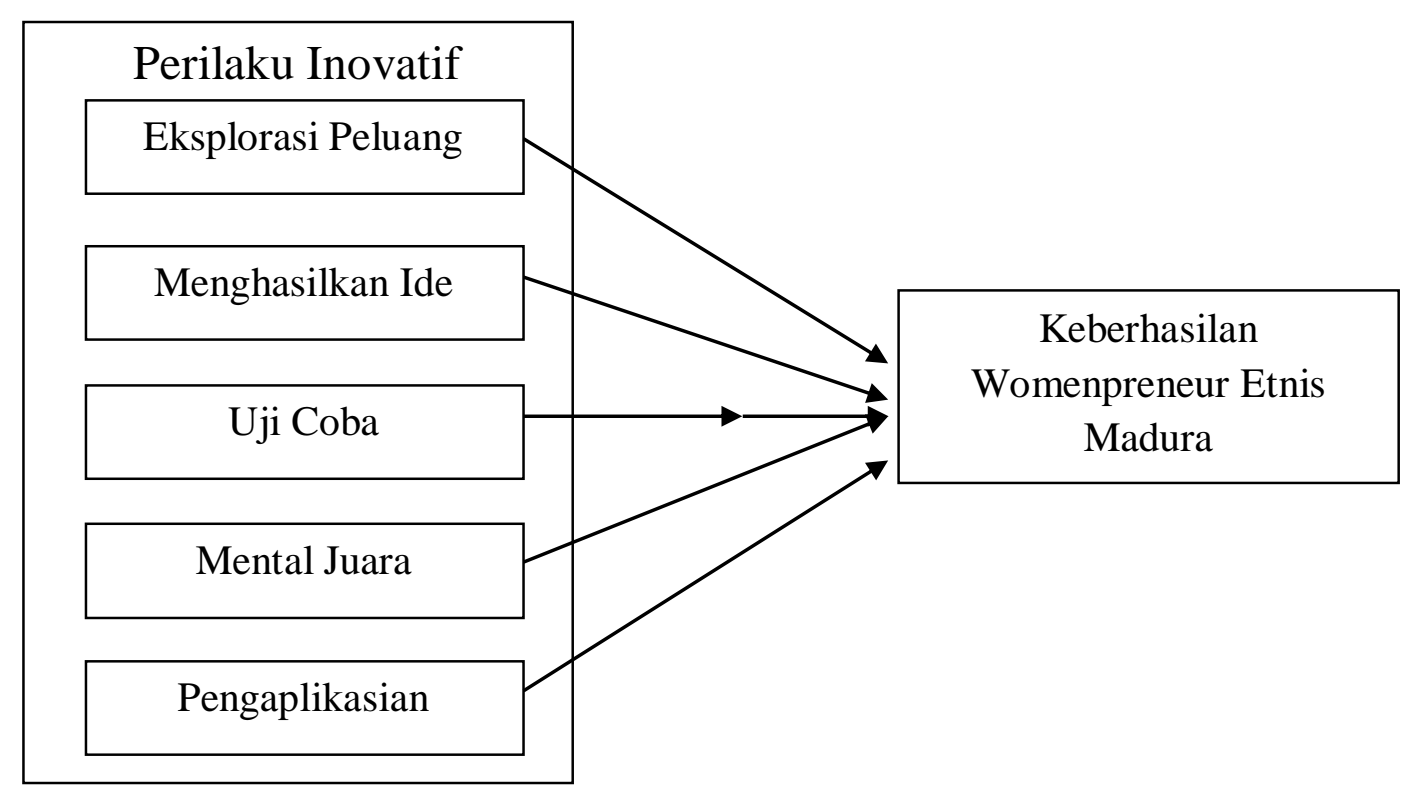

Metode Penelitian

Pendekatan yang dilakukan pada penelitian ini adalah pendekatan kuantitatif dimana variabel-variabel yang diamati dapat diidentifikasikan dan hubungan antar variabel dapat diukur. Data yang dikumpulkan adalah data primer dan sekunder melalui penyebaran kuisioner dan riset kepustakaan sesuai dengan kebutuhan dalam penelitian ini. Penentuan sampel dilakukan dengan menggunakan teknik snowball sampling, yaitu teknik penentuan sampel dengan pertimbangan tertentu. Dalam penelitian jumlah sampel sebanyak 95 womenpreneur yang berdagang pakaian jadi di ITC Mega Grosir Surabaya. Pemilihan tentang womenpreneur yang berdagang pakaian jadi karena jumlah pedagang lebih banyak dan jenis perdagangan ini relatif lebih stabil dibandingkan dengan jenis perdagangan makanan dan minuman di ITC Mega Grosir Surabaya. Lebih stabil yang dimaksudkan dipandang dari sudut komitmen pedagang untuk membuka tokonya, karena berdagang pakaian membutuhkan biaya yang lebih besar dibandingkan dengan berjualan makanan dan minuman, sehingga keinginan untuk selalu membuka toko setiap hari didasari motivasi agar barang dagangannya cepat laku. Motivasi tersebut tentunya tidak sama dengan penjual makanan dan minuman terutama pada etnis Madura yang sangat kental memegang tradisi dan agama sehingga apabila ada libur atau tanggal merah yang terkait dengan hari besar agama dan juga perasaan tradisi mereka rela untuk tidak berjualan dalam jangka waktu yang lama. Untuk menguji pengaruh secara simultan dan parsial dilakukan uji statistik regresi liner berganda dengan sebelumnya juga melakukan uji validitas, uji reliabilitas, uji normalitas, uji multikolinieritas dan uji heterokesdastis.

\section{Pembahasan}

Responden penelitian ini adalah 95 orang womenpreneur etnis Madura yang berdagang pakaian di ITC Mega Grosir Surabaya dengan karakteristik sebagai berikut : Pendidikan : SMA sederajat (65\%), D3 / sederajat (20\%), Sarjana (15\%); Lama usaha : lebih dari 10 tahun (55\%), antara 5 hingga mendekati 10 tahun (30\%), kurang dari 5 tahun (15\%) ; Status Usaha : Melanjutkan usaha orang tua (60\%), usaha sendiri (40\%); Status perkawinan : Sudah menikah 
(100\%) ; Pasangan memiliki pekerjaan lain : Ya (70\%) dan Tidak (30\%) ; Memiliki usaha lain selain di ITC Mega Grosir : Tidak (90\%) ; Ya (10\%)

Uji validitas dilakukan untuk menguji ketepatan item-item pertanyaan kuesioner dalam mengukur variabel penelitian. Teknik yang digunakan adalah korelasi product moment pearson. Suatu item pertanyaan dinyatakan valid jika korelasi product moment pearson menghasilkan koefisien korelasi > 0,3. Perhitungan terhadap variabel perilaku inovatif menghasilkan bahwa semua item pertanyaan pada variabel bebas eksplorasi peluang, menghasilkan ide, uji coba, mental juara dan pengaplikasian memiliki koefisien korelasi $>0,3$. Berdasarkan hasil ini semua item pertanyaan yang mengukur perilaku inovatif sebagai variabel bebas dinyatakan valid dan diikutkan dalam proses analisis selanjutnya.

Sementaa itu pada Pada variabel terikat atau variabel keberhasilan womenpreneur (Y) saat dilakukan putaran pertama pengujian validitas terhadap 15 item pertanyaan, terdapat 1 item yang tidak valid yaitu item pertanyaan $\mathrm{Y}_{15}$. Setelah pertanyaan $\mathrm{Y}_{15}$ dihilangkan, semua item pertanyaan pada variabel terikat keberhasilan womenpreneur telah memiliki koefisien korelasi > 0,3 sehingga dinyatakan valid. Dengan demikian 14 item pertanyaan yang mengukur variabel terikat digunakan dalam proses analisis selanjutnya.

Uji reliabilitas menunjukkan bahwa variabel bebas eksplorasi peluang, menghasilkan ide, uji coba, mental juara dan pengaplikasian, maupun variabel terikat keberhasilan womenpreneur etnis Madura memiliki nilai alpha cronbach >0,6. Berdasarkan hasil ini item-item pertanyaan yang mengukur variabel bebas maupun variabel terikat dinyatakan reliabel.

Uji Normalitas mendapatkan hasil bahwa besarnya nilai signifikan uji kolmogorov smirnov adalah 0,676>0,05, maka disimpulkan bahwa residual model regresi berdistribusi normal, dengan demikian asumsi normalitas residual telah terpenuhi.

Uji Multikolinieritas mendapatkan hasil bahwa nilai tolerance kelima variabel bebas > 0,10 , demikian pula nilai VIF kelimanya $<10$, sehingga dapat disimpulkan model regresi bebas dari multikolinieritas, dengan demikian asumsi tidak ada multikolinieritas telah terpenuhi.

Uji Heteroskesdatis mendapatkan hasil bahwa nilai signifikansi korelasi rank spearman dari kelima variabel bebas > 0,05, maka disimpulkan dalam model regresi tidak terjadi heteroskedastisitas, dengan demikian asumsi tidak ada heteroskedastisitas telah terpenuhi.

Hasil uji hipotesis melalui analisis regresi linier berganda adalah sebagai berikut :

Tabel 1

Hasil Pengolahan Analisis Regresi Berganda

\begin{tabular}{|l|l|l|l|l|}
\hline Model & B & Beta & t & Sig. t \\
\hline Konstanta & 1,768 & & & \\
\hline Eksplorasi Peluang (X1) & 0,080 & 0,149 & 0,962 & 0,342 \\
\hline Menghasilkan Ide (X2) & 0,006 & 0,009 & 0,063 & 0,950 \\
\hline Uji Coba (X3) & 0,044 & 0,069 & 0,487 & 0,629 \\
\hline Mental Juara (X4) & 0,214 & 0,330 & 2,031 & 0,049 \\
\hline Pengaplikasian (X5) & 0,270 & 0,349 & 2,379 & 0,022 \\
\hline R & $=0,716$ & \\
R Square & $=0,513$ & \\
F & $=8,225$ & \\
Sig. F & $=0,000$ & \\
\hline Variabel terikat : Keberhasilan (Y) & \\
\hline
\end{tabular}

Sumber: Hasil perhitungan 

berikut:

Nilai unstandardized coefficient (B) pada Tabel 4.1 diperoleh persamaan regresi sebagai

$$
Y=1,768+0,080 X_{1}+0,006 X_{2}+0,044 X_{3}+0,214 X_{4}+0,270 X_{5}
$$

Nilai korelasi (R) yang diperoleh sebesar 0,716 menunjukkan bahwa hubungan perilaku inovatif yang terdiri dari eksplorasi peluang, menghasilkan ide, uji coba, mental juara, dan pengaplikasian dengan keberhasilan womenpreneur etnis Madura tergolong cukup kuat.

Koefisien determinasi (R Square) yang diperoleh sebesar 0,513 menunjukkan bahwa kemampuan perilaku inovatif yang terdiri dari eksplorasi peluang, menghasilkan ide, uji coba, mental juara, dan pengaplikasian dalam menjelaskan variasi perubahan keberhasilan womenpreneur etnis Madura adalah sebesar 51,3\% dan sisanya 48,7\% dijelaskan oleh faktor lain. Dengan kata lain, keberhasilan womenpreneur etnis Madura dipengaruhi oleh eksplorasi peluang, menghasilkan ide, uji coba, mental juara, dan pengaplikasian sebesar 51,3\%, sedangkan sisanya $48,7 \%$ dipengaruhi oleh faktor lain.

Nilai signifikansi uji $\mathrm{F}$ sebesar $0,000<0,05(\alpha=5 \%)$, maka $\mathrm{H}_{0}$ ditolak dan $\mathrm{H}_{1}$ diterima, sehingga dapat disimpulkan bahwa perilaku inovatif yang terdiri dari eksplorasi peluang, menghasilkan ide, uji coba, mental juara, dan pengaplikasian secara simultan berpengaruh signifikan terhadap keberhasilan womenpreneur etnis Madura. Berdasarkan hasil ini hipotesis pertama penelitian yang menduga perilaku inovatif secara simultan berpengaruh terhadap keberhasilan womenpreneur etnis Madura telah terbukti. Berdasarkan karakteristik responden dapat diketahui bahwa bisnis perdagangan pakaian jadi di ITC Mega Grosir Surabaya merupakan satu-satunya bisnis yang para womenpreneur dapat lakukan untuk turut berperan serta pada pemenuhan kebutuhan keluarga tanpa harus meninggalkan tanggung jawabnya pada pengasuhan anak. Eksistensi mereka dalam berbisnis juga tidak terlepas dari pendidikan menengah hingga tinggi yang mereka tempuh, dimana dengan pendidian yang mereka tempuh mereka dapat melakukan inovasi untuk memperbaiki proses, teknologi, produk dan layanan dalam kegiatan perdagangan sehari-hari. Pernyataan ini sejalan dengan pernyataan Riyanti (2007), bahwa semakin tinggi jenjang pendidikan, maka semakin tinggi pula perilaku inovasi mereka meskipun nantinya pada hipotesis kedua atau uji secara parsial didapatkan hasil yang lebih spesifik dari pengaruh perilaku inovatif pada keberhasilan womenpreneur di ITC Mega Grosir Surabaya.

Nilai signifikansi uji t variabel mental juara $\left(\mathrm{X}_{4}\right)$ dan pengaplikasian $\left(\mathrm{X}_{5}\right)$ masingmasing sebesar 0,049 dan $0,022<0,05(\alpha=5 \%)$, maka $\mathrm{H}_{0}$ ditolak dan $\mathrm{H}_{2}$ diterima, sehingga disimpulkan perilaku inovatif dari segi mental juara dan pengaplikasian secara parsial berpengaruh signifikan terhadap keberhasilan womenpreneur etnis Madura. Akan tetapi hasil uji regresi menghasilkan nilai signifikansi uji t variabel eksplorasi peluang $\left(\mathrm{X}_{1}\right)$, menghasilkan ide $\left(\mathrm{X}_{2}\right)$ dan uji coba $\left(\mathrm{X}_{3}\right)$ masing-masing sebesar 0,342, 0,950 dan 0,629 $>0,05(\alpha=5 \%)$, maka $\mathrm{H}_{0}$ diterima dan $\mathrm{H}_{2}$ ditolak, sehingga disimpulkan perilaku inovatif dari segi eksplorasi peluang, menghasilkan ide dan uji secara parsial berpengaruh tidak signifikan terhadap keberhasilan womenpreneur etnis Madura.

Berdasarkan hasil uji hipotesis kedua penelitian yang menduga perilaku inovatif secara parsial berpengaruh terhadap keberhasilan womenpreneur etnis Madura, hanya terbukti pada mental juara dan pengaplikasian, sedangkan pada eksplorasi peluang, menghasilkan ide dan uji coba tidak terbukti. Apabila dibandingkan dengan aktivitas produksi pakaian jadi, ktivitas perdagangan pakaian tidak menuntut para womenpreneur di ITC Mega Grosir Surabaya untuk melakukan aktivitas eksplorasi peluang, menghasilkan ide dan uji coba seperti halnya usaha kuliner, karena para pedagang tidak terlibat dari proses perancangan model baju yang sedang digemari masyarakat hingga penjahitan, mereka hanya melakukan kegiatan jual beli 
saja.Wirausaha etnis Madura memang mengabaikan aspek studi kelayakan bisnis, karena mereka tidak terbiasa untuk melakukan hal itu, sehingga hitung - hitungan sederhana lebih penting asalkan tidak rugi. Bagi mereka yang terpenting adalah peluang pemasaran dan ketersediaan barang dagangan, karena buat apa memiliki usaha kalau tidak ada yang membeli (Agustina,2014)

Jika dilihat dari faktor jenjang pendidikan yang mayoritas SMA, maka kegiatan eksplorasi peluang ini tidak maksimal dapat berjalan. Pernyataan ini juga sekaligus menjelaskan bahwa kegiatan berdagang tidak harus menuntut pendidikan tinggi, namun apabila dikaitkan dengan perilaku inovasi tentunya jenjang pendidikan ini akan berpengaruh, seperti yang dinyatakan oleh Hammond, et al (2011) bahwa . individu yang memperoleh pengetahuan dan pengalaman, lebih akan membangun dan mengintegrasikan gagasan, fakta, dan peluang sehingga menghasilkan ide yang kreatif terhadap permasalahan.

Selain itu keterbatasan mobilitas karena harus menjalankan peran sebagai womenpreneur sekaligus ibu rumah tangga juga menjadi kendala yang mereka temui untuk melakukan eksplorasi peluang lebih jauh. Hal itu senada dengan pernyataan Hendratni dan Ermalina (2017) bahwa perempuan pengusaha mikro seringkali terbatasi oleh mobilitas fisik dan kultur komunitasnya.

Sedangkan pengaruh parsial aktivitas mentalitas juara dan pengaplikasian terhadap keberhasilan womenpreneur etnis Madura di ITC Mega Grosir Surabaya dapat dikaitkan dengan karakteristik responden yang menjalankan peran sebagai istri sekaligus ibu rumah tangga yang berkeinginan untuk membantu suami dalam hal pemenuhan kebutuhan finansial keluarga. Hasil ini mendukung temuan penelitian Madjid, F, dan Handayani (2012) bahwa keputusan wanita yang sudah menikah dimotivasi karena ingin berkontribusi pada perekonomian rumah tangga.

Selain itu usaha perdagangan yang mereka lakukan adalah meneruskan usaha yang sudah dirintis oleh orang tua mereka didukung pula tidak ada usaha lain yang dijalankan selain berdagang di ITC Mega Grosir Surabaya mendorong mereka untuk dapat mempertahankan eksistensi usaha mereka. Pernyataan tersebut sejalan dengan pemdapat penelitian Sukesi, Wisaptiningsih dan Nurhadi, (2008) yang menyatakan bahwa etos kerja yang tinggi pada wanita Madura didorong dengan keyakinan bahwa kerja adalah ibadah, amal serta sebagai bentuk perjuangan meraih pengakuan atas kemampuan dirinya.

\section{Kesimpulan}

Berdasarkan hasil uji statistik dan analisis yang telah dilakukan dirumuskan simpulan pada penelitian ini adalah sebagai berikut : Perilaku inovatif secara simultan terbukti berpengaruh terhadap keberhasilan womenpreneur etnis Madura

Secara parsial, mental juara dan pengaplikasian sebagai dimensi dari perilaku inovatif berpengaruh pada keberhasilan womenpreneur etnis Madura. Sedangkan eksplorasi peluang, menghasilkan ide dan uji coba terbukti tidak berpengaruh pada keberhasilan womenpreneur etnis Madura.

Saran yang diberikan pada penelitian ini adalah : sebaiknya mompreneur etnis Madura dalam berdagang pakaian jadi di ITC Megagrosir Surabaya dapat lebih meningkatkan perilaku inovatif yang dimilikinya terutama dari sisi eksplorasi peluang, menghasilkan ide, uji coba. Selain itu mereka dapat lebih memaksimalkan networking yang mereka miliki untuk mengatasi kendala-kendala mobilitas yang womenpreneur temui sehingga dapat bermanfaat untuk menunjang keberhasilan usaha mereka Dengan kata lain segala aspek perilaku inovatif 
INOBIS: Jurnal Inovasi Bisnis dan Manajemen Indonesia

Volume 03, Nomor 02, Maret 2020

Tri Siwi Agustina

seharusnya diterapkan secara rutin untuk mencapai dan meningkatkan keberhasilan usaha secara nyata.

\section{Daftar Pustaka}

Agustina, TS., 2014, Mengungkap Perilaku Inovatif 3 etnis wanita pedagang di Surabaya, Jurnal Manajemen Teori dan Terapan Tahun 7. No. 1, April 2014. https://ejournal.unair.ac.id/JMTT/article/download/2683/1949

Cowerman, S. 1989. 'Role overload, role conflict, and stress: Addressing consequences of multiple role demands, Social Forces, 67(4) 965-82

De Jong, J. P. J. and Kemp, R., 2003, "Determinants of co-workers' innovative behaviour: an investigation into knowledge intensive services." International Journal of Innovation Management, Vol. 7 No. 2, pp. 189-212.

De Jong, J \& Hartog, D D. 2003. Leadership as a determinant of innovative behaviour. A Conceptual framework. http://www.eim.net/pdf-ez/H200303.pdf. 21 April 2006

Druker, Peter F. 1991. "The Discipline of Innovation", dalam Innovation, A Harvard Bussiness Review No. 90072. New York. President and Fellows of Harvard College.

Hammond, M., Neff, N.L., Farr, J.L., Schwall, A.R., \& Zhao, X. (2011). Predictors of individuallevel innovation at work: A meta-analysis. Psychology of Aesthetics, Creativity, and the Arts, 5, 90. Doi: 10.1037/a0018556

Hendratni TW dan Ermalina, 2017, Womanpreneur, Peranan Dan Kendalanya Dalam Kegiatan Dunia Wirausaha, http://ojs.itb-ad.ac.id/index.php/LQ/article/view/119, DOI https://doi.org/10.32546/lq.v2i2.119

Idris, A., 2008, Cultivating Innovation through Female Leadership: The Malaysian Perspective, Asian Social Science, Vol.4, No. 6.

Kleysen, R.F., \& Street, C.T., 2001. Toward a multi-dimensional measure of individual innovative behavior. Journal of Intellectual Capital. Vol. 2, No. 3, 1469-1930. Diunduh tanggal 24 Juli 2013

Madjid, F, dan Handayani., 2012, Faktor-Faktor Yang Mempengaruhi Keputusan Perempuan Berstatus Menikah Untuk Bekerja (Studi Kasus Kota Semarang), Diponegoro Journal of Economics, Vol 1 (1),

Moeliono, A, 1989. Kamus Besar Bahasa Indonesia, Kementrian Pendidikan Nasional RI, Jakarta.

Nurhadi, I, dkk. 2008. Indigenous Knowledge Tentang Spirit Dan Energi Sosial Potensial Perempuan Madura Dalam Konteks Perubahan Sosial Di Indonesia : Laporan Penelitian. Malang: PDII

Sandjaja, U.P \& Riyanti., B. P. D., 2004. Pengembangan Model Perilaku Berwirausaha yang Inovatif pada Perusahaan-Perusahaan kecil, Lembaga Penelitian, Unika Atmajaya

Sutarto, Ayu. 2006. Bende Media Informasi Seni dan Budaya. Surabaya. Pemerintah Provinsi Jawa Timur Dinas Pendidikan dan Kebudayaan Taman Budaya.

Stain, HB.,1989. The Female Entrepreneur Multi-attributional Casuality. Lexington. MA. Lexington Books

Tambunan, Tulus T.H.. 2009. UMKM di Indonesia. Jakarta: Ghalia Indonesia.

Teoh, WMY dan Chong SC, 2008 , Improving Women Entrepreneurs in Small and Medium Enterprises in Malaysia: Policy Recommendations, https://www.researchgate.net/publication/45258172_Improving_Women_Entrepreneu rs in Small and Medium Enterprises in Malaysia Policy Recommendations 
INOBIS: Jurnal Inovasi Bisnis dan Manajemen Indonesia

Volume 03, Nomor 02, Maret 2020

Tri Siwi Agustina

Walker, E \& Brown, 2004, What Success Factors are Important to Small Business Owners?. International Small Business Journal, 22; hal 577-594. 